\title{
A UNESP e a linguística brasileira
}

\author{
Ataliba T. de Castilho \\ Professor Emérito da Universidade de São Paulo (USP), São Paulo, São Paulo, Brasil \\ Professor Titular Colaborador da Universidade Estadual de Campinas (UNICAMP), \\ Campinas, São Paulo, Brasil \\ ataliba@uol.com.br
}

DOI: http://dx.doi.org/10.21165/el.v46i1.1740

\section{Resumo}

Historio neste trabalho a implantação da Linguística na UNESP, indicando os principais rumos tomados por essa ciência nos diversos campi da universidade.

Palavras-chave: Linguística; Universidade Estadual Paulista; português brasileiro; língua falada; gramáticas; dicionários.

\section{São Paulo State University and the Brazilian linguistics}

\begin{abstract}
In this paper I deal with the establishment of Linguistics in the Sao Paulo State University, stressing the fields chosen by first linguists in various campi of this University.
\end{abstract}

Keywords: Linguistics; Sao Paulo State University; Brazilian Portuguese; spoken language; grammars; dictionaries.

Até o final dos anos 1950, os brasileiros interessados em estudar Linguística tinham apenas três possibilidades em nosso país: os cursos de Joaquim Mattoso Câmara Jr., na Universidade do Distrito Federal, hoje Universidade Federal do Rio de Janeiro, os de Theodoro Henrique Maurer Jr., na Universidade de São Paulo, e os de Rosário Farâni Mansur Guérios, na Universidade Federal do Paraná.

No caso dos paulistas, essa situação começou a mudar quando o então Governador do Estado de São Paulo, Prof. Alberto Carvalho Pinto, tomou medidas para a interiorização da indústria, do comércio e do ensino superior, este sob a gestão da Coordenadoria de Ensino Superior do Estado de São Paulo, CESESP.

Para a extensão do ensino superior, não havia massa crítica tarimbada para atuar nos novos institutos de ensino superior. Eram então escolhidos recém-licenciados, com curso de Especialização, desde que indicados por professores catedráticos da USP. Esses professores tinham cinco anos de prazo para doutorar-se. Lembre-se que à altura o Mestrado e o Doutorado não estavam escolarizados, como hoje. Também ocorreu a nomeação de alguns especialistas conhecidos, que concordassem em mudar-se para cidades do interior paulista.

Os professores eram contratados em tempo integral, havia dinheiro para montar bibliotecas e laboratórios, e adaptar os prédios então disponíveis até que, mais tarde, fossem construídos os campi do interior. Se não estou enganado, Assis foi o primeiro Instituto a dispor de prédio construído especialmente para esse fim. 
Fui nomeado para Marília, em que encontrei um colega de turma, o Enzo Del Carratore. Outro colega de turma foi designado aqui para Assis, o João de Almeida. Também aqui em Assis começou sua carreira o historiador Jaime Pinsky, hoje Diretor da Editora Contexto. E com eles, muitos outros pesquisadores.

Os antigos Institutos Isolados do Ensino Superior, administrados pela CESESP, foram integrados em 1976 na UNESP, a terceira universidade oficial paulista por ordem de fundação.

A nova universidade dispõe hoje em dia de unidades em todo o Estado de São Paulo: Araraquara, Assis, Bauru, Botucatu, Dracena, Guaratinguetá, Ilha Solteira, Itapeva, Jaboticabal, Presidente Prudente, Registro, Rio Claro, Rosana, São João da Boa Vista, São José do Rio Preto, São José dos Campos, São Paulo, São Vicente, Sorocaba e Tupã. Os cursos de Letras originais continuaram em Araraquara, Assis e São José do Rio Preto, tendo sido fechados os de Marília e Franca.

Ainda no tempo da CESESP, os professores de Língua Portuguesa, Latim e de Linguística de Assis, Marília e Araraquara começamos a trocar figurinhas, com o objetivo de delinear uma política científica para essas áreas. Havia liberdade para isso. As instituições eram novas, sem os ranços do passado que complicam às vezes a vida de instituições mais antigas.

Essa política viria a ter consequências positivas, com que não contávamos à altura. Ela se constituiu a partir de respostas às seguintes perguntas: Que faziam as universidades de São Paulo, Rio de Janeiro e Paraná? Que faríamos nós?

- Eles faziam Linguística histórica? Então nós faríamos Linguística descritiva.

- Eles estudavam a língua escrita? Então nós estudaríamos a língua falada, mesmo não sabendo a confusão em que estávamos nos metendo.

- Eles estudavam a România Velha, investigando a mudança do latim vulgar para o Português? Então nós nos concentraríamos na România Nova, lidando com o português e o espanhol da América.

- E quanto à documentação e descrição das línguas indígenas do Brasil? Alguns professores, como o Paulo Froehlich de Marília, se ocuparam disso.

- As atividades acadêmicas por que tínhamos passado em nossos bancos escolares concentravam-se em aulas e em nada mais? Então, além das aulas, organizaríamos seminários, para preencher aspectos incompletos de nossa formação e para apresentar trabalhos, recrutando novas vocações.

- Quando estudávamos, não havia divulgação das pesquisas por meio de revistas especializadas? Então Assis fundou a Revista de Letras, e Marília a revista Alfa, atualmente revista de Linguística da UNESP.

Estávamos nisso quando surgiram no horizonte dos cursos de Letras, por decisão federal, as disciplinas de Linguística e de Teoria Literária, aquela obrigatória, esta facultativa. Vou me fixar na primeira delas.

A moderna Linguística estabeleceu-se no Brasil nos anos 1970, o que quer dizer que os professores nomeados para os Institutos Isolados não tinham cursado essa disciplina em sua graduação. Havia uma exceção de que o João, o Enzo e eu nos beneficiamos: como ex-alunos de Letras Clássicas, na USP, tínhamos estudado 
Linguística Indo-Europeia e Filologia Românica, ambas fundamentadas no método histórico-comparativo. Nosso professor, Theodoro Henrique Maurer Jr., demonstrava em suas aulas e publicações que a agenda desse método estava longe de ser esgotada.

De lá para cá muita coisa mudou. Apenas para lembrar: o I Seminário de Linguística de Marília, realizado em 1966, reuniu todos os linguistas brasileiros de então, escassamente uns 15 ou 20. Contrastando com isso, a Associação Brasileira de Linguística e o Grupo de Estudos Linguísticos do Estado de São Paulo, associações fundadas em 1969, por propostas apresentadas naquele seminário, ultrapassam hoje o milhar de associados. Isso, sem falar nas muitas associações regionais de Linguística que atuam no país, inspiradas no exemplo do GEL: o CELLIP, o GELNE, o GELNO, entre outras.

Como todo movimento científico que estreia, a Linguística brasileira precisava escolher um inimigo. Escolhemos dois: a Filologia, entendida como edição crítica de textos, sobretudo antigos, e a Gramática tradicional.

Ora, como diz o ditado, "aqui se faz, aqui se paga". A Filologia voltou nos anos 1990, trazida pelo ressurgimento da Linguística Histórica. A Gramática tradicional foi substituída por gramáticas escritas por linguistas, a partir dos anos 1980.

É impossível detalhar todos esses resultados, no espaço de uma conferência. Vou então me restringir a três deles: (i) documentação e descrição do português brasileiro falado, (ii) preparação de dicionários, (iii) preparação de gramáticas e estudos gramaticais. Como os presentes já perceberam, essas áreas de pesquisa continuam ativas, chegando aos dias de hoje. Mesmo assim, posso ter cometido algumas omissões neste texto, todas involuntárias.

\section{Documentação e descrição do português brasileiro falado}

A partir dos anos 1970, grupos de pesquisadores afiliados a várias universidades brasileiras se engajaram na tarefa de documentar, descrever e refletir sobre a língua falada.

Em toda a sua história, a Linguística sempre esteve atravessada pela ideia de que a língua falada é a manifestação primordial da linguagem e seu objeto primeiro de estudos. Mas esses belos propósitos só puderam se transformar em ações efetivas depois de uma inovação tecnológica, a invenção do gravador portátil. Podia-se, finalmente, pôr em marcha um programa sistemático de investigação da oralidade.

A documentação e a descrição do português falado por meio de projetos coletivos compreendeu várias iniciativas. Limitando-me à ação da UNESP, ou com sua forte participação, enumero o Projeto de Estudo da Norma Urbana Culta Falada no Brasil, ou Projeto NURC, e o Projeto Amostra Linguística do Interior Paulista.

Outras universidades brasileiras também operaram nesse campo, mas neste momento vou dar vazão ao meu patriotismo estadual.

Um dos pioneiros nesse lance lecionava aqui em Assis, o Pedro Caruso. Seu projeto, Atlas Linguístico do Estado de São Paulo, seguiu os passos de Nelson Rossi, da Bahia. A Dialetologia sempre se fundamentou no estudo da língua falada. Caruso não pôde completar seu projeto, que foi levado a cabo por Vanderci Aguilera, quando veio 
doutorar-se aqui em Assis, sob sua orientação. Não é preciso relembrar a explosão por que passa nos dias de hoje a preparação de atlas linguísticos.

Vejamos mais de perto as pesquisas sobre esses temas, concentrando-nos no Projeto NURC e no Projeto ALIP.

\subsection{O Projeto NURC}

O intercâmbio estabelecido entre a revista Alfa e várias universidades do país e do exterior garantia um bom fluxo de publicações e de informações para os marilienses, nos tempos em que a revista estava ali sediada.

Entre essas, apareceu um dia o folheto Noticias Culturales, do Instituto Linguístico Caro y Cuervo, de Bogotá. Lia-se ali que em 1964, Juan M. Lope Blanch, linguista espanhol radicado no México, tinha obtido junto ao Programa Interamericano de Linguística e Ensino de Idiomas (PILEI) a aprovação de seu Proyecto de Estudio Coordinado de la Norma Lingüística Culta de las Principales Ciudades de Iberoamérica y de la Península Ibérica: Lope Blanch (1964/1967, 1986).

Seu projeto apresentava uma notável mudança de rumo nos estudos dialetológicos: deixava-se de privilegiar o falar residual de pequenas comunidades rurais, "perdidas en los varicuetos de una sierra", como ele dizia, partindo-se para a documentação e análise da linguagem padrão das grandes metrópoles que iam surgindo, as quais alteraram a proporção "população rural x população urbana" na organização demográfica das nações latino-americanas. Lope Blanch mostrava, por exemplo, que em vários países da América Latina metade da população habitava suas capitais, o que poderia afetar o espanhol falado no país, dada a previsível força de irradiação da variedade da capital.

Achei incrível aquilo: migrar da dialetologia rural para a dialetologia urbana, documentando e descrevendo a língua falada da România Nova, tudo isso ajeitava num balaio só duas das nossas bandeiras cesespianas! Escrevi logo uma adaptação do projeto para o estudo do português do Estado de São Paulo, num texto intitulado "Descrição do Português Culto na Área Paulista" (CASTILHO, 1968), que submeti à crítica de vários colegas. Comecei por Lope Blanch e por Nelson Rossi, com os quais me encontrava regularmente, como delegado brasileiro junto ao PILEI. Esse programa faleceu nas mãos do Aryon Dall'Igna Rodrigues, no final dos anos 1990, rebatizando-se esse importante programa de PILEI para PIFEI.

Eu não sabia, mas desde o começo, o Proyecto previa a inclusão da América Portuguesa, além da Espanha e Portugal. Convidado a opinar sobre o assunto, o Prof. Nélson Rossi, da Universidade Federal da Bahia, um dos delegados brasileiros junto ao PILEI, apresentou uma proposta ao Simpósio do México (1968). Ele pondera ali que, contrariamente à América Espanhola, a execução do projeto no Brasil não poderia limitarse à capital do país, e nem mesmo ao Rio de Janeiro: "arrisco a impressão de que a cidade do Rio de Janeiro, apesar de sua excepcional significação como aglomerado urbano e como centro de irradiação de padrões culturais, não daria por si só a imagem do português do Brasil” (ROSSI, 1968/1969, p. 49).

E olhem que o Rossi era carioca! Ele desenvolve então suas ideias sobre o policentrismo cultural brasileiro, argumentando que, desenvolvendo-se o projeto em cinco capitais, quatro fundadas no séc. XVI (Recife, Salvador, Rio de Janeiro e São 
Paulo), e uma no séc. XVIII (Porto Alegre), estariam abarcados "doze milhões e meio de habitantes aproximadamente, o que equivale a um sétimo da população atual do país" (ibidem).

Convidado por Nelson Rossi a integrar o projeto mais amplo, aceitei suas ponderações e desisti do plano anterior.

Finalmente, a 11 de janeiro de 1969, aproveitando a presença de vários professores brasileiros reunidos no III Instituto Interamericano de Linguística, promovido pelo PILEI na Universidade de São Paulo, juntamente com o II Congresso Internacional da Associação de Linguística e Filologia da América Latina (ALFAL), então presidida por Mattoso Câmara Jr., o Prof. Rossi convocou uma reunião de que participaram os futuros coordenadores das equipes do Projeto, que viria a ser conhecido entre nós como "Projeto NURC": Albino de Bem Veiga (Porto Alegre), Isaac Nicolau Salum e Ataliba T. de Castilho (São Paulo), além do próprio Nelson Rossi, coordenador do Projeto em Salvador. Posteriormente, seriam indicados Celso Cunha (Rio de Janeiro) e José Brasileiro Vilanova (Recife). Reuni num livrinho editado pelo Conselho Municipal de Cultura de Marília os documentos então gerados (CASTILHO, 1970).

Designadas as equipes locais, cuja listagem aparece em Castilho (1990, p. 147149), teve início o trabalho de documentação da fala de 600 informantes de formação universitária, selecionados entre pessoas nascidas na cidade, filhas de pais igualmente nascidos na cidade, divididos por igual em homens e mulheres, distribuídos por três faixas etárias (25-35 anos, 36-55 e de 56 em diante).

A fala dos informantes foi gravada em três situações distintas: diálogo com o documentador (DID), diálogo entre dois informantes (D2) e aulas e conferências (EF). A equipe nacional desistiu de realizar as gravações sigilosas previstas no projeto original. As entrevistas eram tematicamente orientadas, fundamentando-se em cerca de 20 centros de interesse, abrangidos por mais de 4.000 quesitos. A metodologia de tudo isso e o acompanhamento da pesquisa eram regularmente discutidos em reuniões nacionais do projeto, de que se realizaram 14, entre 1969 e 1987.

As gravações foram realizadas entre 1970 e 1977, tendo-se apurado um corpus gigantesco, constante de 1.870 entrevistas com 2.356 informantes, totalizando 1.570 horas de gravações. Começou então a árdua tarefa de transcrever parte desse corpus, organizando-se o "corpus compartilhado", um conjunto de dezoito entrevistas de todas as cidades, selecionadas de acordo com os parâmetros sociolinguísticos do projeto. Amostras do corpus começaram a ser publicados em 1986:

- São Paulo: Castilho e Preti (1986; 1987), Preti e Urbano (1988);

- Rio de Janeiro: Callou (1992), Callou e Lopes (1993; 1994);

- Salvador: Motta e Rollemberg (1994; 2006);

- Recife: Sá Cunha, Lima e Oliveira (1996; 2005);

- Porto Alegre: Hilgert (1997).

O Centro de Documentação Linguística e Literária Alexandre Eulálio, do Instituto de Estudos da Linguagem (IEL) da UNICAMP dispõe de todos esses materiais, que estão sendo digitalizados para disponibilização eletrônica. 
De acordo com a metodologia do Projeto, a análise dos materiais assim recolhidos se faria a partir de um Guia-Questionário, visando assegurar a comparabilidade dos resultados a obter nas cinco cidades. A comissão brasileira adaptou a versão espanhola já publicada desse roteiro: Cuestionario $(1971 ; 1973)$. Os quesitos compreendiam três setores: Fonética e Fonologia, Morfossintaxe e Léxico.

As análises dos materiais começaram em 1978. Duas grandes direções marcaram essas análises: (i) estudos gramaticais e (ii) estudos de pragmática da língua falada. Parte desses trabalhos foi publicada em coletâneas: Castilho (1989a, b), Preti; Urbano (1990), Preti (1993, 1997, 1998, 2000, 2002). Muitos textos foram publicados em revistas científicas e anais de congressos, outros são teses, como Menon (1994). O estudo do léxico do Rio de Janeiro foi preparado por Marques (1996). O estudo do léxico de São Paulo foi empreendido por Del Carratore e Laperuta (2009). Para a história do Projeto NURC e a bibliografia gerada até 1990, ver Castilho (1990).

As análises gramaticais já em 1981 mostravam que haveria problemas para a continuação dos trabalhos, na forma como eles tinham sido concebidos no final dos anos 60 pelo projeto congênere do Espanhol da América: (1) não tinha havido uma discussão sobre a especificidade do oral, e os instrumentos de análise fundamentavam-se, na verdade, na língua escrita; (2) o modelo teórico adotado, que combinava elementos da Gramática Tradicional com uma sorte de "Estruturalismo mitigado", não dava conta de uma série de fenômenos típicos da modalidade falada; (3) novas tendências da indagação linguística, surgidas posteriormente à concepção do projeto, mostravam-se mais sensíveis à modalidade falada, particularmente as aproximações entre a Sintaxe e o Discurso. Para uma análise dessas e de outras questões, ver Castilho $(1984,1990)$. Deixo claro que não se tratava de falhas no projeto original, apenas de novas áreas que foram surgindo, simultaneamente a ele.

Apesar desses acidentes de percurso, deve-se reconhecer que esse projeto se mostrou plenamente vitorioso em sua fase de coleta e organização dos dados, e de implantação da oralidade na agenda dos linguistas brasileiros. Graças a ele, a Linguística brasileira se manteve atualizada quanto à organização e estudos da língua falada, como demonstrei em outro lugar. Mas o Projeto NURC chegaria a um alvo inesperado, que caracterizarei na 3.2 deste texto.

\subsection{A Amostra Linguística do Interior Paulista (ALIP)}

Esta seção se fundamenta em texto escrito pelo colega Sebastião Carlos Gonçalves, da UNESP/São José do Rio Preto, contribuição que agradeço, igualmente por ter permitido sua inclusão aqui.

Considerando os avanços da pesquisa sociolinguística no Brasil nas últimas décadas, pode-se afirmar que os estudos variacionistas sobre as variedades paulistas ainda se encontram na sua infância. Estamos, portanto, em dívida com a formulação do retrato sociolinguístico do Português Brasileiro (PB), no que toca ao oferecimento de um espectro mais amplo da fala paulista.

Em outras palavras, comparados a trabalhos variacionistas envolvendo outras variedades do PB (citem-se aqui as variedades cariocas, catarinenses, paranaenses, gaúchas, mineiras, paraibanas, dentre outras), podem-se considerar escassos os trabalhos nessa mesma linha envolvendo a fala paulista, seja a da capital, seja a do interior. 
Seria injusto, entretanto, deixar de lembrar aqui que as variedades paulistas já tinham sido objeto de estudos, ainda que não sob enfoque sociolinguístico. Citem-se, nessa direção, os estudos descritivos desenvolvidos no âmbito do Projeto Gramática do Português Falado Culto (CASTILHO, 1990) e os que vêm se desenvolvendo no interior do projeto "Para a história do português paulista" ou "Projeto Caipira", o qual confere lugar de destaque à investigação das variedades paulistas do PB, assumindo como objetivo principal "investigar emparelhadamente a formação da sociedade paulista e de suas variedades linguísticas, tais como testemunhadas no Estado de São Paulo e em sua capital" (CASTILHO, 2009a, p. 15).

Num balanço crítico da pesquisa variacionista produzida no Estado de São Paulo, Gonçalves (2012) mostra que só muito recentemente a Sociolinguística vem se firmando no Estado, em torno de três projetos de maiores dimensões: o projeto "Amostra Linguística do Interior Paulista" (GONÇALVES, 2006, 2007, 2008), o projeto "Estilos na cultura popular e urbana" (SILVA, 2010) e o projeto "SP2010 - Construção de uma Amostra da Fala Paulistana" (MENDES, 2011), sediados, respectivamente, na Universidade Estadual Paulista (UNESP/São José do Rio Preto), na Universidade Estadual de Campinas e na Universidade de São Paulo.

Gonçalves registra ainda o pioneirismo dos trabalhos etnolinguísticos sobre a variedade paulista advindo das contribuições de Amadeu Amaral (1976), em $O$ dialeto caipira, de Ada Natal Rodrigues (1974), sobre o dialeto caipira de Piracicaba, e o de Mary Careno (1997), sobre a fala de comunidades negras do Vale do Ribeira, além dos trabalhos variacionistas de Duarte (1986), sobre a realização de objeto direto anafórico na fala de paulistanos nativos e na linguagem da televisão, e de Rodrigues (1987), sobre concordância verbal na fala de favelados da capital paulista.

Ciente dessa carência de estudos sociolinguísticos sobre variedades paulistas, sobretudo do interior do estado, Sebastião Carlos Gonçalves instituiu, no ano de 2003, o projeto ALIP, motivado pelos interesses de pesquisas que tinham como principal diretriz o enfoque da língua inserida em seu contexto social.

O projeto se constituiu sob os auspícios da Fundação de Amparo à Pesquisa do Estado de São Paulo - FAPESP, tendo por objetivo primeiro a composição de um banco de dados com amostras do português falado na região de São José de Rio Preto, recurso fundamental para a consolidação de grupos de pesquisa e para a proposição de projetos coletivos de pesquisa.

Embora inspirado em outros projetos já consolidados (VARSUL, PEUL, VALPB, Gramática \& Discurso), o projeto ALIP não assumiu como prerrogativa para sua proposição interessar-se por qualquer fenômeno linguístico em particular, mas, sob uma concepção mais ampla e mais aberta, manteve a preocupação de captar o máximo possível do dinamismo linguístico da região noroeste do Estado de São Paulo, representada por São José do Rio Preto e seis outras cidades que lhe fazem fronteira: Bady Bassit, Cedral, Guapiaçu, Ipiguá, Mirassol e Onda Verde. Assim, entre os anos de 2004 a 2007, foi constituído o Banco de Dados Iboruna (= "rio preto", em Tupi), composto por dois tipos de amostras de fala: a primeira, coletada de acordo com os critérios da Sociolinguística laboviana (LABOV, 1972), constitui a Amostra Censo ou Amostra Comunidade, e a segunda, coletada secretamente em 
contextos interacionais livres, sem controle de qualquer variável social (RONCARATI, 1996), constitui a Amostra de Interação. ${ }^{1}$

$\mathrm{Na}$ composição da Amostra Censo, foram controladas as variáveis sociais comprovadamente relevantes nos estudos sociolinguísticos, a saber: sexo/gênero; faixa etária (7 a 15 anos, 16 a 25 anos, 26 a 35 anos, 36 a 55 anos, mais de 55 anos), escolaridade ( $1^{\circ}$ ciclo do ensino fundamental; $2^{\circ}$ ciclo do ensino fundamental, ensino médio e ensino superior) e renda familiar (até 5 salários mínimos, 6 a 10 salários mínimos, 11 a 25 salários mínimos e mais de 25 salários mínimos). ${ }^{2}$

Do cruzamento das variantes dessas variáveis resultou um total de 152 perfis sociais, dos quais apenas um ainda não foi encontrado na comunidade. A inclusão de área geográfica como mais uma variável de estratificação faria crescer consideravelmente o número de informantes. Assim, para a execução do censo linguístico, os 152 perfis sociais foram distribuídos proporcionalmente por entre as sete cidades da região, considerando a densidade populacional mostrada no quadro 1 a seguir.

Quadro 1. Distribuição dos perfis sociais proporcionalmente à densidade populacional das cidades da região

Fonte: IBGE. Censo 2000

\begin{tabular}{|l|c|c|}
\hline \multicolumn{1}{|c|}{ Cidades da Região de São José do Rio Preto } & População & Número de informantes \\
\hline 1. Bady Bassit (12 km, ao sul de SJRP) & 11.475 & 04 \\
\hline 2. Cedral (14 km, ao sul de SJRP) & 6.690 & 02 \\
\hline 3. Guapiaçu (16 km, ao leste de SJRP) & 14.049 & 05 \\
\hline 4. Ipiguá (18 km, ao norte de SJRP) & 3.461 & 01 \\
\hline 5. Mirassol (14 km, a oeste de SJRP) & 48.233 & 16 \\
\hline 6. Onda Verde (25 km, ao norte de SJRP) & 5.407 & 02 \\
\hline 7. São José do Rio Preto & 357.705 & 122 \\
\hline Total da população representada & 447.020 & 152 \\
\hline
\end{tabular}

A definição do perfil social desses informantes por cidade seguiu o método da distribuição aleatória por área geográfica, que consiste nos seguintes procedimentos: (i) em uma primeira urna, foram recolhidos todos os perfis sociais, identificados pelos números de 1 a 152; (ii) em uma segunda urna, foram depositados os nomes de todas as cidades da região; (iii) por meio de escolha ao acaso, retirou-se de cada uma das urnas um perfil social e um nome de cidade, definindo-se assim a origem geográfica do perfil social; (iv) em seguida, devolvia-se para a segunda urna o nome da cidade escolhida, até que se atingisse o seu número de informantes; (v) nova escolha combinada era feita, até

\footnotetext{
${ }^{1} \mathrm{O}$ nome IBORUNA (= Rio Preto) tem motivação histórica; é um topônimo de origem tupi-guarani que se pretendeu atribuir à cidade de São José do Rio Preto por ocasião da comemoração do seu cinquentenário. A contundente intervenção do episcopado riopretense não só impediu a mudança como conquistou de maneira definitiva a denominação primitiva, São José do Rio Preto, reduzida a Rio Preto de 1906 a 1944.

${ }^{2}$ Cabe aqui uma rápida justificativa acerca da proposição de algumas variantes: no recorte contínuo de faixas etárias, a primeira representa a fase em que os padrões linguísticos estão ainda em fixação; da segunda em diante, a motivação é buscada na pressão social sobre a linguagem do indivíduo, variável de acordo com a inserção no mercado de trabalho (cf. SILVA, 1996); a segmentação das variantes de escolaridade, embora pedagogicamente extinta nos dois primeiros ciclos, preserva diferenças salientes em termos de currículo e metodologia de ensino e representa a divisão escolar em vigor no tempo em que a maioria dos informantes se enquadrava; sobre a variável renda familiar, reconhecendo a dificuldade de divisão de classe social por indicadores diversos, optamos apenas por esse indicador.

${ }^{3}$ Inclui os Distritos de Talhados e Engenheiro Schmidt.
} 
ser definida a origem geográfica de todos os informantes. Esse procedimento permitiu assegurar a probabilidade de quaisquer dos perfis sociais pertencerem a uma dada cidade.

Definidos os perfis sociais, a constituição de Amostra Censo, incluindo a localização dos perfis na comunidade, a gravação e a validação da entrevista e sua posterior transcrição ficou sob a responsabilidade de uma equipe técnica composta, na primeira fase do projeto, por 30 integrantes. ${ }^{4}$ Seguindo roteiro previamente elaborado, as entrevistas de AC foram direcionadas para obtenção de cinco tipos de textos de cada informante, com base na metodologia exposta em Votre e Oliveira (1995), a saber: narrativa de experiência pessoal, narrativa recontada, relato de descrição, relato de opinião e relato de procedimento.

Para a constituição da Amostra Interação, pautada por orientações metodológicas e éticas (RONCARATI, 1996), integrantes da mesma equipe coletaram 11 amostras de interação social livre, cujas descrições são dadas no Quadro 2.

Quadro 2. Informações sobre as interações dialógicas de AI

\begin{tabular}{|l|l|}
\hline AMOSTRA & CONTEXTO DE INTERAÇÃO-INFORMANTES ENVOLVIDOS \\
\hline AI-001-CAS & $\begin{array}{l}\text { Conversa entre dois homens e cinco mulheres de diferentes idades e escolaridades, em } \\
\text { ambiente familiar. }\end{array}$ \\
\hline AI-002-GIL & $\begin{array}{l}\text { Diálogo entre duas amigas vizinhas, com perfis sociais semelhantes, no portão da casa } \\
\text { de uma delas. }\end{array}$ \\
\hline AI-003-ILHA & Diálogo entre tia e sobrinha, de diferentes idades e escolaridades, em ambiente familiar. \\
\hline AI-004-OND & $\begin{array}{l}\text { Diálogo entre duas irmãs, de mesma faixa de idade e diferentes escolaridades, em } \\
\text { ambiente familiar. }\end{array}$ \\
\hline AI-005-CAS & Diálogo entre duas estudantes de mesmo perfil social, em ambiente universitário. \\
\hline AI-006-MAR & Conversa entre quatro mulheres de perfis sociais diferentes, em ambiente familiar. \\
\hline AI-007-FER & $\begin{array}{l}\text { Diálogo entre marido e esposa de mesma faixa etária e de niveis de escolaridade } \\
\text { diferentes, em ambiente familiar. }\end{array}$ \\
\hline AI-008-CAM & $\begin{array}{l}\text { Conversa entre três estudantes, do sexo masculino e mesmos perfis sociais, em ambiente } \\
\text { universitário. }\end{array}$ \\
\hline AI-009-CAS & $\begin{array}{l}\text { Diálogo entre um advogado e sua cliente, de perfis sociais diferentes, em escritório de } \\
\text { advocacia. }\end{array}$ \\
\hline AI-010-CAS & $\begin{array}{l}\text { Discussão entre dois advogados, de mesmo perfil social, sobre uma peça jurídica, em } \\
\text { escritório de advocacia. }\end{array}$ \\
\hline AI-011-CAS & $\begin{array}{l}\text { Diálogo entre casal de namorados, estudantes universitários de mesma faixa etária, em } \\
\text { ambiente familiar. }\end{array}$ \\
\hline
\end{tabular}

$\mathrm{Na}$ fase final do projeto, a preparação definitiva da Amostra Censo e da Amostra Interação ficou sob responsabilidade de quatro integrantes da equipe técnica, aos quais coube a tarefa de revisão minuciosa da documentação linguística de cada uma das gravações armazenadas no banco de dados: as transcrições e os respectivos áudios, as fichas sociais, as fichas de validação e os diários de campo. Além desse material, encontram-se disponíveis também no site do projeto (www.iboruna.ibilce.unesp.br) os relatórios de cada fase do projeto, o manual de transcrição e o roteiro de entrevistas. ${ }^{5}$

Próximo de completar sua primeira década de existência, o projeto ALIP e o banco de dados Iboruna já propiciaram importantes trabalhos descritivos da fala do interior

\footnotetext{
${ }^{4}$ Compuseram a equipe um pesquisador coordenador geral, seis pesquisadores colaboradores e 23 auxiliares técnicos.

${ }^{5}$ Para maiores informações sobre questões teóricas e metodológicas do projeto ALIP, remetemos o leitor a Gonçalves (2008).
} 
paulista, tanto da perspectiva sociolinguística quanto de uma perspectiva funcionalista, não variacionista, de modo que um retrato sociolinguístico da região já começa a se esboçar.

Da perspectiva variacionista, os fenômenos já investigados contemplam os níveis fonético-fonológico e morfossintático. Integrados ao "Projeto de descrição sóciohistórica das vogais do português brasileiro" (PROBRAVO), que tem por objetivo descrever as realizações fonéticas de vogais nos dialetos de Sul a Norte do Brasil, trabalhos variacionistas envolvendo o dialeto paulista vêm se consolidando no Estado de São Paulo, sob a coordenação da Profa. L. E. Tenani, da UNESP de São José do Rio Preto, a exemplo da descrição de outros dialetos que têm lugar no interior do projeto nacional, a saber: dialetos mineiros, dialetos do Sul, dialeto da Paraíba, dialeto matogrossense, dialeto do Pará, dialeto de Rondônia, dialeto capixaba, dialeto baiano e dialeto carioca. ${ }^{6}$ Mais especificamente, com base nas amostras de fala do banco de dados Iboruna, as contribuições com PROBRAVO incluem resultados para os seguintes fenômenos variáveis: (i) alçamento vocálico em contextos de pretônica média de nomes, como em $c$ [o]zinha $\sim c[$ u]zinha e t[e]soura $\sim$ t/i]soura (SILVEIRA, 2008), e de verbos, como em d[e]via $\sim d[$ i]via e $p[o] d i a \sim p$ [u]dia (CARMO, 2009); (ii) alçamento e síncope de postônicas mediais, como em pês.s[e].go pês.s[i].go pês.go e a.bó.[bo].ra a.bó.[bu].ra a.bó.[bra] (RAMOS, 2009).

Não diretamente ligados ao PROBRAVO, outros fenômenos fonéticos também já dispõem de resultados interessantes. Um exemplo é o trabalho de Ferreira (2010) sobre a redução de gerúndio, como em canta[ndo] canta[no], traço marcante da fala paulista interiorana, que alcança percentuais elevadíssimos de aplicação da alternante reduzida $(72 \%)$, frente a outras variedades.

Resultados para fenômenos variáveis de ordem morfossintática incluem a expressão de futuro sintético $x$ futuro analítico (FONSECA, 2010); a expressão de aspecto cursivo por meio de perífrases verbais, como em andar $x$ continuar $x$ ficar $x$ viver + gerúndio (FERNANDES, 2010); a realização de preposições com $x$ sem contração, como em com $a \sim c u^{\prime} a \sim c^{\prime} a$, para pra pa etc. (MARCATO, 2013); a expressão de cópula em orações matrizes predicativas, como em é claro que claro que (FORTILLI, 2013); a alternância indicativo/subjuntivo em orações complexas (SANTOS, 2005); a marcação de plural em sintagmas nominais (FIAMENGUI, 2011) e em contextos de predicativo (SALOMÃO, 2010); a concordância verbal de 3PP (RUBIO, 2008) e padrões de concordância verbal e de alternância pronominal (RUBIO, 2012).

O banco de dados Iboruna tem servido ainda ao desenvolvimento de inúmeras pesquisas de descrição do português falado sob a perspectiva funcionalista, não variacionista. Dentre as várias pesquisas já concluídas, citemos: o uso de marcadores discursivos (GUERRA, 2007; PENHAVEL, 2010), a gramaticalização de juntivos (FELÍCIO, 2008; GALBIATI, 2010; SOUZA, 2009; RENCK, 2011), a gramaticalização e a combinação de orações (GONÇALVES, 2011; SANTANA, 2010), a expressão de

\footnotetext{
${ }^{6} \mathrm{O}$ PROBRAVO, composto por pesquisadores de 17 universidades brasileiras, foi criado em 2005 com sede na Universidade Federal de Minas Gerais, é atualmente coordenado pelos Profs. S. Lee e M. A. Oliveira. De modo articulado, vem procurando responder às seguintes questões: (i) como são realizadas foneticamente as vogais no PB? (ii) como se explica ou o que motiva a diversidade de realizações fonéticas? (iii) como os falantes do PB se entendem, apesar das diversidades da qualidade vocálica? (iv) é possível explicar essa diversidade gramaticalmente? (Informações disponíveis em: $<$ http://relin.letras.ufmg.br/probravo $>$. Acesso em: 10 fev. 2012).
} 
evidencialidade (VENDRAME, 2010) e o uso de predicações não verbais (FORTILLI, 2007).

Rotulado, de modo mais amplo, de sociofuncionalista, outro conjunto de trabalhos vem sendo desenvolvido, combinando-se as perspectivas da variação e da gramaticalização. Incluem-se nessa vertente a investigação de preposições com verbos de movimento (WIEDEMER, 2013), a alternância nós $x$ a gente (NARDELLI, 2016; ROSSAFA, 2016), o alçamento de constituintes (GONÇALVES, 2015) e as predicações reduzidas encaixadas em predicados avaliativos (LIMA, 2014).

\section{A UNESP e a preparação de dicionários}

Mencionarei nesta seção a preparação de dicionários gramaticais e dicionários históricos por linguistas da UNESP.

\subsection{Dicionários gramaticais}

A partir dos anos 1980, Francisco da Silva Borba - que foi o primeiro Secretário do GEL e que leciona na UNESP/Araraquara desde a fundação dessa unidade - deu início à organização de um vasto corpus de língua escrita, de que resultaram muitos trabalhos, entre dicionários e gramáticas. Sobre o Corpus de Araraquara, ver Neves (2013, p. 295314).

Em 1990, Borba publicou o seu Dicionário gramatical de verbos do português contemporâneo do Brasil. Em 2002, publicou o Dicionário de usos do português do Brasil. Em 2005, o Dicionário UNESP do português contemporâneo. Ele traz, no prelo, o Dicionário documentado do Português do Brasil.

Em todos esses casos, atuou como coordenador geral, reunindo uma grande equipe de pesquisadores.

\subsection{Dicionários históricos}

Os dicionários históricos indicam a data em que as palavras entraram na língua. Preparar um dicionário histórico é um empreendimento gigantesco, que envolve a manipulação de um corpus extenso, e de um extremo cuidado na redação dos verbetes.

Maria Teresa Biderman e Clotilde de A. Azevedo Murakawa, da UNESP/Araraquara, a primeira já falecida, coordenaram vários pesquisadores para a preparação de seu Dicionário Histórico do Português do Brasil - séculos XVI, XVII e XVIII, fundamentado num corpus de 10 milhões de ocorrências. A versão impressa em papel A4 demanda 11.051 páginas, com 19 volumes.

Os verbetes trazem a mudança semântica das palavras, sua etimologia, e a data em que elas apareceram documentadas, nos diferentes tipos de documento. Vários dicionários, como o Houaiss, têm-se valido desse trabalho para retrodatar suas entradas.

No domínio do Projeto para a História do Português Brasileiro, Vanderci Aguilera e Fabiane Cristina Altino trazem em preparação o Léxico Histórico do Português Brasileiro, em que estão compilando as palavras do corpus respectivo. 


\section{A UNESP e a preparação de gramáticas}

Como disse anteriormente, na instalação da Linguística no Brasil, malhar a gramática tradicional era nosso esporte favorito, praticado entusiasticamente nos seminários, nos congressos, e nas revistas.

Depois que nos cansamos disso, passamos a escrever gramáticas, optando uns pelo trabalho coletivo, outros pelo trabalho individual. Nesse meio tempo, surgiram os grupos de funcionalistas, que têm publicado importantes estudos monográficos. Relato essas atividades nesta seção.

\subsection{Gramáticas monoautorais}

Pela ordem cronológica, e limitando-me à contribuição da UNESP, temos nesta categoria primeiramente Maria Helena de Moura Neves, com sua monumental Gramática de Usos do Português, de 2000, com 1037 páginas, fundamentada num vasto corpus de análise, o já mencionado Corpus de Araraquara.

Peço licença para mencionar minha Nova Gramática do Português Brasileiro, de 2010, mesmo tendo deixado a CESESP em 1975.

Nesse trabalho, optei por me afastar deliberadamente do gênero "gramática", apesar do título, tendo tomado as seguintes iniciativas:

(1) Não redigi uma gramática-lista, que se detém nas classificações, em que se vê uma gramática, não uma língua. Em lugar disso, procuro olhar o que se esconde por trás das classificações, identificando os processos criativos do português brasileiro que conduziram aos produtos listados.

(2) Esta não é uma gramática a-teórica. Nada poderemos fazer em matéria de pesquisa linguística se não dispusermos de alguma teoria, pois lidamos com um objeto escondido em nossas mentes, como Saussure já havia reconhecido. Teorias linguísticas há muitas. Mas faz falta uma teoria que postule a língua em seu dinamismo, como um conjunto articulado de processos - abundantemente reconhecidos e descritos pelos pesquisadores do Projeto de gramática do português falado, PGPF. Enfrento esta questão nesta gramática. Quando falamos ou quando escrevemos, uma intensa atividade é desencadeada em nossas mentes. Isso ocorre com enorme rapidez, acionando os quatro sistemas linguísticos: Léxico, Semântica, Discurso, Gramática. A Abordagem multissistêmica exposta em Castilho (2010a) e na Nova gramática do Português Brasileiro tem um forte conteúdo funcionalistacognitivista. Reconheço que ainda é impossível descrever todos os movimentos mentais envolvidos na atividade linguística. Mas não há dúvida de que em cada som emitido, em cada sinal gráfico lançado ao papel, toma corpo um enorme conhecimento linguístico que foi ativado, permitindo o milagre da compreensão mútua por meio de tão poucos sons e letras, e de tão escassas palavras e construções. Para visualizar esse conhecimento, precisaremos valorizar os indícios da maquinaria linguística. A língua falada revela com fartura esses indícios. Basta ter olhos para identificá-los.

(3) As gramáticas se fundamentam habitualmente na língua literária. Também aqui minha gramática tomou outro rumo. Para começo de conversa, não acho que os escritores trabalham para nos abastecer de regras gramaticais. Eles exploram ao máximo as potencialidades da língua, segundo um projeto estético próprio, afastando-se com vigor do "uso comum" da língua. Ainda bem! Ora, as regularidades que as gramáticas 
identificam devem fundamentar-se nesse uso comum, quando conversamos, quando lemos jornais, como cidadãos de uma democracia. Isso não exclui obviamente a fruição das obras literárias, mas é uma completa inversão de propósitos fundamentarnos nelas para descrever uma língua. Minha gramática se insere nesse quadro de preocupações. Filtrei aqui as pesquisas das últimas três décadas a partir de uma ótica própria, propondo seguidamente ao leitor que se envolva na investigação, transformando-se no linguista-gramático dele mesmo. Seguindo esse impulso, minha gramática dá voz a muitos desses pesquisadores, tanto quanto às aulas que fui ministrando ao longo de 60 anos de magistério. Meus alunos me ajudaram muito, com sua curiosidade e com sua recusa a explicações não convincentes. Havia também uns poucos tomados de um grande tédio. Esses também me ajudaram, pois me mostravam que a aula estava um bocado chata, ou seja, eu não tinha conseguido naquele espaço de tempo desvelar as maravilhas da linguagem.

(4) O ritmo expositivo de nossas gramáticas adota o que se poderia chamar de "estilo revelação". O gramático se transforma numa espécie de Moisés que desce dos altos montes com as tábuas da lei, barba esvoaçando ao vento, e brada aos povos estupefatos, anticlimaticamente, o que está certo e o que está errado em sua linguagem! Também aqui me distanciei disso. Imaginei para tanto a seguinte estratégia: compus dois textos articulados, um expositivo, e outro indagativo. $\mathrm{Na}$ exposição, falo eu, interpretando os achados da ciência atual. Nas indagações, falam os leitores, por meio das perguntas que imagino que eles estejam formulando. $\mathrm{O}$ objetivo dessa estratégia é transformar os leitores numa espécie de coautores, recusando que entre eles e a língua que praticam seja obrigatória a interposição de um intérprete, de uma espécie de despachante para problemas gramaticais. Para dar conta desse lance meio calvinista, apresentei perguntas e mais perguntas nas páginas da Nova Gramática do Português Brasileiro, ao lado de informações sobre o conhecimento disponível e o fornecimento de pistas sobre como achar novas respostas. Para evitar uma aborrecida listagem de opiniões, que poderia obscurecer o objeto, optei por interpretar os resultados obtidos à luz da já mencionada Abordagem multissistêmica da língua. Depois disso, apresento algumas generalizações sobre o retrato do português brasileiro assim obtido. Novas perguntas conducentes à reflexão gramatical foram formuladas no capítulo 15 , em que apresento a metodologia da pesquisa linguística.

\subsection{Gramáticas coletivas}

Dadas as dificuldades da análise gramatical ocorridas no Projeto NURC, apresentei em 1987 à Associação Nacional de Pesquisa e Pós-Graduação em Letras e Linguística (ANPOLL), a convite da Profa. Maria Helena de Moura Neves, da UNESP de Araraquara, um projeto de preparação coletiva de uma gramática do português falado, com base nos materiais do Projeto NURC/Brasil.

Tendo havido boa receptividade à ideia, convoquei em 1988 o I Seminário desse projeto, no qual se debateu o plano inicial, que era o de "preparar uma gramática de referência do português culto falado no Brasil, descrevendo seus níveis fonológico, morfológico, sintático e textual".

Reconheceu-se nesse primeiro encontro que seria impossível selecionar uma única articulação teórica que desse conta da totalidade dos temas que se espera ver debatidos numa gramática de referência como a que se planejava escrever. As primeiras discussões 
cristalizaram esse reconhecimento, tendo-se decidido dar livre curso à convivência dos contrários no interior do projeto.

Como forma de organização, os 32 pesquisadores que atuaram no projeto, afiliados a 12 das maiores universidades brasileiras, distribuíram-se por Grupos de Trabalho (GTs), sob a coordenação de um deles, para a realização das tarefas previamente agendadas:

(1) Fonética e Fonologia, coordenado inicialmente por João Antônio de Moraes, e posteriormente por Maria Bernadete M. Abaurre.

(2) Morfologia Derivacional e Flexional, coordenado por Margarida Basílio e Ângela C. S. Rodrigues, respectivamente.

(3) Sintaxe das Classes de Palavras, coordenado inicialmente por Rodolfo Ilari, e posteriormente por Maria Helena de Moura Neves.

(4) Sintaxe das Relações Gramaticais, coordenado inicialmente por Fernando Tarallo, e posteriormente por Mary Kato.

(5) Organização Textual-Interativa, coordenado por Ingedore G. V. Koch.

Cada GT traçou o perfil teórico que pautaria suas pesquisas. Entre 1988 e 1998 foram realizados dez seminários plenos, ao longo dos quais os textos apresentados eram reformulados e publicados em uma série própria, editada pela UNICAMP, em oito volumes, com apoio da FAPESP:

(1) Castilho $(1990,1993)$.

(2) Ilari (1992).

(3) Castilho e Basílio (1996).

(4) Kato (1996).

(5) Koch (1996).

(6) Neves (1999).

(7) Abaurre e Rodrigues (2002).

A Fundação de Amparo à Pesquisa do Estado de São Paulo (FAPESP) financiou as atividades, também apoiadas vez e outra pelo Conselho Nacional de Pesquisas.

A partir de 1990, os pesquisadores pediram ao Prof. Milton do Nascimento que debatesse os problemas teóricos suscitados pelos trabalhos apresentados, na qualidade de Assessor Acadêmico do PGPF. Isso ocorreu sistematicamente desde o IV Seminário, resultando daí alguns textos, um dos quais apresentado por ele ao Centro de Linguística da Universidade de Lisboa, em 1993, em reunião convocada pelos Drs. Maria Fernanda Bacelar do Nascimento e João Malaca Casteleiro: Nascimento (1993a, b). Com suas análises, o Milton estava lançando um projeto paralelo, o de desenvolver generalizações, desenvolver teorias linguísticas, um ponto ainda não atingido pela Linguística Brasileira. Ele e vários colegas trabalham duramente nisto, no âmbito do grupo Complex Cognitio, da PUC de Minas Gerais.

O Milton, modestamente, não reconhece esse seu papel. Mas um fato é um fato e como dizia o Prof. Laga, colega de Marília, diante de um fato devemos tirar o chapéu. É o que faço agora. Se entre vocês houver, como espero, interessados em elaborações 
teóricas, peço que leiam Paiva e Nascimento (2009) e meus ensaios "Approach to language as a complex system" e "Interação linguística e descrição do português brasileiro" (CASTILHO, 2009a-e, 2015). Mas isso é assunto para outra ocasião.

Encerrada a agenda do PGPF, deu-se início em 2003 à consolidação dos resultados obtidos entre 1990 e 2003.

Destaco aqui, nessa fase, a enorme importância das pesquisas de uma colega egressa desta casa, a Profa. Clélia Cândida Spinardi Jubran, que organizou o primeiro volume dessa fase de consolidação, em que também atuou a Mercedes Sanfelice, outra colega de Assis.

O trabalho da Clélia merece uma análise cuidadosa, pois juntamente com Ingedore Koch, ela desenvolveu uma teoria sobre a organização social interativa do texto. É preciso estudar e expor essa teoria, num campo tão versado no Brasil como é a Linguística do Texto. Sua teoria teve várias repercussões, de que mencionarei duas, pedindo licença para começar por mim mesmo.

(1) Em 2007, concebi a Abordagem multissistêmica das línguas, que dispõe de um dispositivo sociocognitivo, largamente devedor às ideias da Ingedore e da Clélia: Castilho (2007, 2009 a, b, 2010 a, b, 2012b), Castilho e Moraes de Castilho (2011, 2013a). Não há tempo para detalhar isso agora.

(2) Poucos anos atrás, Roger Costa escreveu sua dissertação de mestrado na PUC/MG, intitulada Organização tópica da conversação, em que ele examina este ponto da teoria do texto formulada pela Clélia. Outros orientandos do Prof. Milton do Nascimento, daquela mesma universidade, vêm esmiuçando as ideias da nossa querida Clélia. Fico feliz por trazer esta informação aos colegas de Assis.

O ex-professor desta casa, Jaime Pinsky, publicou a segunda edição dos três primeiros volumes, publicados anteriormente pela Editora da UNICAMP, completando essa série, graças ao que temos hoje uma coleção de 7 volumes, todos eles publicados pela Editora Contexto, com apoio da FAPESP:

- Vol. 1 - Clélia Jubran (2015).

- Vol. 2 - Mary Kato e Milton do Nascimento (2015).

- $\quad$ Vol. 3 - Rodolfo Ilari (2014).

- $\quad$ Vol. 4 - Rodolfo Ilari (2015).

- Vol. 5 - Maria Helena de Moura Neves (2016).

- Vol. 6 - Ieda Maria Alves e Ângela Cecília S. Rodrigues (2015).

- Vol. 7 - Maria Bernadete M. Abaurre (2013).

Esses volumes serão lançados neste seminário. Todos estão convidados, quando mais não seja, porque dos oito organizadores desses volumes, três começaram suas carreiras na UNESP: Clélia, em Assis, Maria Helena em Araraquara, Ieda e Ataliba em Marília.

A articulação teórica desses volumes consta das respectivas Apresentações, escritas por seus organizadores. Isso já tinha acontecido anteriormente, na série dos 8 
volumes de ensaios. Preparei uma síntese desses debates todos, que saiu como Apresentação da segunda edição do volume I: Jubran (2015, p. 9-25).

Duas perspectivas teóricas inconciliáveis à altura separavam os pesquisadores: a perspectiva formal e a perspectiva funcional sobre a linguagem. Depois de algumas tentativas iniciais de catequese, todas frustradas, combinou-se que os formalistas, abrigados nos GTs de Sintaxe, de Morfologia e de Fonologia, e os funcionalistas, abrigados nos GTs de Organização textual-interativa e de Classes de palavras, seguiriam seu caminho, encontrando-se anualmente nos seminários plenos, para compartilhar os resultados obtidos.

Ocorreu, entretanto, uma inesperada convergência.

Acontece que a maior expectativa que as pessoas alimentam ao consultar uma gramática de referência é encontrar ali, devidamente hierarquizado, um conjunto de produtos linguísticos, o chamado enunciado, dispostos em planos classificatórios mais ou menos convincentes.

Ora, a Gramática do Português Culto Falado no Brasil deixou de lado essa estratégia, tendo buscado identificar os processos acionados para a produção do enunciado. Indo nesta direção, Nascimento (1993b, p. 433-438) propôs que o texto é "o lugar onde é possível identificar as pistas indicadoras das regularidades que caracterizam a atividade linguística do falante". Ponto para a Ingedore e para a Clélia! Neves (2013) e Camacho (2013) - todos eles da UNESP - elaboraram essas ideias.

Outros pontos de convergência tinham sido assinalados por Mary Kato, na introdução ao vol. V, por ela organizado (KATO, 1996, p. 9-32).

O fato é que, em suma, procurando os produtos, toparam os pesquisadores com os processos constitutivos da língua, mais evidentes na modalidade falada. É por isso que todos os volumes da série de consolidação têm por subtítulo a palavra "construção": construção do texto, da sentença, das classes de palavras, construção morfológica da palavra, construção fonológica da palavra.

O fato é que já não basta mais identificar e catalogar produtos. Agora é preciso identificar os processos de que eles resultaram.

\subsection{Estudos monográficos funcionalistas}

Desde 2000, a UNESP de São José do Rio Preto sedia o Grupo de Pesquisa em Gramática Funcional (GPGF), sob a liderança de Erotilde Goreti Pezatti e a vice-liderança de Roberto Gomes Camacho, com a finalidade de promover debates e aprofundar estudos em Gramática Funcional. Agradeço a Roberto Camacho por ter-me enviado um relato de onde retirei os elementos mencionados a seguir.

O maior grupo de estudiosos da escola funcionalista holandesa no Brasil é o de São José do Rio Preto. Essa escola foi nucleada, inicialmente, em torno da Teoria da Gramática Funcional (GF) de Simon Dik $(1989,1997)$ e, atualmente, em torno de seu discípulo, Kees Hengeveld, que, em coautoria com John Lachlan Mackenzie, lançou as bases da chamada Gramática Discursivo-Funcional (GDF) (HENGEVELD; MACKENZIE, 2008).

O modelo adotado é conhecido como Gramática Discursivo-Funcional, apresentada em Neves (2013, p. 31-34). Segundo Maria Helena de Moura Neves (2013, 
p. 32), esse modelo "coloca como unidade básica do discurso o ato discursivo, e não a frase", num movimento de cima para baixo. Citando Hengeveld, Neves (2013, p. idem, ibidem) menciona "a assunção de que as decisões dos níveis e camadas de análise mais elevados determinam e restringem as possibilidades dos níveis e camadas de análise mais baixos". Trata-se, portanto, de um modelo que opera com a postulação de camadas nas línguas naturais - o que procede do Estruturalismo -, e, ainda, com a aceitação de que há regras de determinação entre esses níveis ou camadas.

O sumário do livro organizado por Pezatti (2009) dá uma boa ideia da temática que vem sendo tratada pelo grupo: advérbios e complementos adverbiais, nominalização, tópico novo em narrativas, modalização, predicados evidenciais, marcadores discursivos e conjunções, sentenças condicionais.

Por volta do ano de 2002, Roberto Gomes Camacho sugeriu que as pesquisas envolvendo os membros do grupo como autores ou como orientadores fossem voltadas para uma amostra da própria variedade rio-pretense, o que daria maior consistência também ao Programa de Pós-Graduação em Estudos Linguísticos. A ideia tomou corpo e Sebastião Carlos Leite Gonçalves, então membro ativo do GPGF, lançou o projeto ALPI, já aqui mencionado. O bonito dos projetos coletivos de pesquisa é exatamente isso, sua capacidade de reduplicar-se, ampliando nossos horizontes científicos.

O GPGF conta atualmente com 12 membros docentes, 11 membros estudantes de diversos níveis (doutorado, mestrado e iniciação científica), e um colaborador estrangeiro, a Profa. Hella Gertrud Olbertz. As linhas de pesquisa que o grupo desenvolve são "Descrição funcional de língua falada e língua escrita" e "Tipologia Linguística".

A linha "Descrição funcional da língua falada e escrita" deu lugar a projetos tais como "As preposições no português do ponto de vista da GDF" (PEZATTI et al., 2010). Partindo do pressuposto de que, apesar de a tradição gramatical tratar as preposições como elementos exclusivamente gramaticais, reconheceu-se que o estatuto dessa classe não está claramente delimitado. Investigou-se a hipótese de que, em português, algumas preposições, que constituem predicados monovalentes, são itens lexicais, enquanto outras, que funcionam como marcadores de funções semânticas, são operadores gramaticais.

Outro projeto é o das "Construções subordinadas nas variedades lusófonas: uma abordagem discursivo-funcional". Nesse caso específico, a amostra em que se buscaram as evidências é a do "Projeto Português Falado - Variedades Geográficas e Sociais", desenvolvida pelo Centro de Linguística da Universidade de Lisboa - CLUL (2009), em parceria com a Universidade de Toulouse-le-Mirail e a Universidade de Provence-AixMarseille (BACELAR, 2006).

Desse trabalho coletivo, resultou uma coletânea, organizada por Pezatti (no prelo) que se compõe de duas partes: a primeira trata da subordinação dentro da oração, e a segunda é dedicada à subordinação dentro do sintagma. Na camada da oração, incluemse as de argumento (completiva e predicativa) e as de modificadores, comumente entendidas como adverbiais. $\mathrm{Na}$ segunda parte, dedicada à subordinação dentro do sintagma, também se incluem uma subordinada argumental, tradicionalmente denominada completiva nominal, e uma modificadora, mais conhecida por oração relativa ou adjetiva. Alguns resultados desse projeto foram publicados em Fontes e Pezatti (2012), Novaes-Marques e Pezatti (2015), e um conjunto expressivo de dissertações de 
mestrado e teses de doutorado (GARCIA, 2010; OLIVEIRA, 2011; SPOSITO, 2012; STASSI-SÉ, 2012; CÂMARA, 2015).

A linha "Tipologia linguística" foi explorada no projeto "Transparência e opacidade nas línguas indígenas do Brasil", de que resultou o trabalho coletivo Hengeveld et al. (2007), que trata de ilocuções nas línguas nativas do Brasil. Esse trabalho resultou do workshop "Modality in Brazilian Portuguese", assentado em bases tipológicas, que foi ministrado por Kees Hengeveld em 2004.

Pretende-se, nesse projeto, investigar os fatores que levam ao compartilhamento ou não compartilhamento de traços transparentes entre as línguas, tomando-se como corpus 20 línguas indígenas descritas em gramáticas e teses, que representam 12 diferentes famílias linguísticas. Como resultado, espera-se (i) comparar os dados de modo e determinar as características compartilhadas; (ii) estabelecer hierarquias implicacionais; e, por conseguinte, (iii) determinar, qualitativamente, o grau de transparência de cada língua analisada.

Na mesma linha de pesquisa, destacam-se ainda os estudos não coletivos (i) sobre modalidade (HENGEVELD; DALL'AGLIO HATTNHER, 2015; DALL'AGLIO HATTNHER; HENGEVELD, 2016), que centram o interesse na identificação dos níveis de atuação das categorias modais e (ii) sobre estratégias de relativização em línguas indígenas (GIMENEZ, 2011, OLIVEIRA; CAMACHO, 2013).

Em seu conjunto, as pesquisas do grupo de funcionalistas de São José do Rio Preto mostram a absoluta necessidade de levar em conta a atuação dos falantes no momento da criação de construções textuais, gramaticais e semânticas. Esses trabalhos permitem visualizar a consolidação das pesquisas numa gramática funcionalista do PB mais sensível ao uso - tarefa que, certamente, em algum momento será enfrentada por esse grupo.

\section{Conclusões}

Neste breve histórico dos estudos linguísticos desenvolvidos por iniciativa da CESESP e da UNESP, muito provavelmente deixei de relatar outras atividades, por desconhecimento deles. Mas espero ter deixado clara a enorme importância das lideranças que foram surgindo nesta universidade, e, mais recentemente, da produção científica dos programas de pós-graduação.

Um projeto de pesquisa, coletivo ou individual, toma por ponto de partida algumas perguntas, cujas respostas nos levam, sempre, a novas perguntas e, com elas, a novos projetos. Neste texto, auto-limitei-me às iniciativas da UNESP. Com isso, não pude falar, por exemplo, do Projeto para a História do Português Brasileiro, iniciativa da USP, que vai chegando aos seus 20 anos, com uma já vasta produção.

São patentes as contribuições dadas pelos pesquisadores que vieram para a UNESP e por aqueles que se formaram aqui. Quanto ao campus de Assis, para além do que ficou dito, permitam que lhes sugira o fortalecimento de sua tradição de pesquisas, com a retomada necessária do curso de pós-graduação em estudos linguísticos. 


\section{REFERÊNCIAS}

ABAURRE, M. B. M.; RODRIGUES, Â. C. S. (Org.). Gramática do Português Falado. v. VIII. Campinas: Editora da UNICAMP, 2002.

ABAURRE, M. B. M. (Org.). Construção fonológica da palavra. Gramática do Português Culto Falado no Brasil. v. VII. São Paulo: Editora Contexto, 2013.

AGUILERA, V. de A. (Org.). Para a História do Português Brasileiro. v. VII: vozes, veredas, voragens, 2 tomos. Londrina: Editora da Universidade Estadual de Londrina, 2009.

ALKMIM, T. (Org.). Para a História do Português Brasileiro. v. III. Novos Estudos. São Paulo: Humanitas / Universidade de São Paulo; Instituto de Estudos da Linguagem / Universidade Estadual de Campinas, 2002.

ALVES, I. M.; RODRIGUES, Â. C. (Org.). Construção morfológica da palavra. Gramática do Português Culto Falado no Brasil. v. VI. São Paulo: Editora Contexto, 2015.

AMARAL, A. O dialeto caipira. 3. ed. São Paulo: Hucitec-SCET-CEC, 1976 [1920].

BACELAR DO NASCIMENTO, M. F. Corpora comparáveis e variação lexical nas variedades africanas do português. Alfa, São Paulo, v. 50, n. 2, p. 189-204, 2006.

CALlOU, D. I. (Org.). A Linguagem Falada Culta na Cidade do Rio de Janeiro. Materiais para seu estudo. v. I: Elocuções Formais. Rio de Janeiro: UFRJ/FJB, 1992.

CALLOU, D. I.; LOPES, C. R. (Org.). A Linguagem Falada Culta na Cidade do Rio de Janeiro. Materiais para seu estudo. v. II. Diálogo entre Informante e Documentador. Rio de Janeiro: UFRJ/CAPES, 1993.

. (Org.). A Linguagem Falada Culta na Cidade do Rio de Janeiro. Materiais para seu estudo. v. III. Diálogos entre dois informantes. Rio de Janeiro: UFRJ/CAPES, 1994.

CAMACHO, R. G.; SANTANA, L. Argument structure of deverbal nouns in Brazilian Portuguese. Journal of Language and Linguistics, v. 3 (2), p. 229-242, 2004.

CAMACHO, R. G. Classes de palavras na perspectiva da Gramática DiscursivoFuncional. O papel da nominalização no continuum categorial. São Paulo: Editora da UNESP, 2011.

. Da Linguística formal à Linguística social. São Paulo: Parábola, 2013.

CÂMARA, A. L. A oração relativa em português: interface entre a descrição e o ensino. 2015. 177 f. Tese (Doutorado em Estudos Linguísticos) - Instituto de Biociências, Letras e Ciências Humanas, Universidade Estadual Paulista Júlio de Mesquita Filho, São José do Rio Preto, 2015.

CARENO, M. F. Vale do Ribeira: a voz e a vez das comunidades negras. São Paulo: Arte \& Ciência/UNIP, 1997.

CARMO, M. C. As vogais médias pretônicas dos verbos na fala culta do interior paulista. 2009a. 122 f. Dissertação (Mestrado em Estudos Linguísticos) - Instituto de Biociências, Letras e Ciências Exatas, Universidade Estadual Paulista, São José do Rio Preto, 2009a.

CARUSO, P. Amostra de um inquérito linguístico prévio para o Estado de São Paulo. Alfa, 26, p. 69-77, 1982. 
. Atlas Linguístico do Estado de São Paulo: questionário. Assis: Instituto de Letras, História e Psicologia da UNESP / Prefeitura Municipal de Assis, 1983.

CASTILHO, A T. de. Descrição do português culto na área paulista. Letras de Hoje, 4, p. 73-78, 1968.

. (Org.). Projeto de descrição do português culto falado no Brasil. Marília: Conselho Municipal de Cultura, 1970.

El Proyecto de Estudio Coordinado de la Norma Culta. Formalismo y semanticismo en la sintaxis verbal. In: SOLÁ, D. F. (Ed.). Language in the Americas. Proceedings of the Ninth PILEI Symposium. Ithaca: Cornell University, 1984. p. 161165.

. (Org.). Português Culto Falado no Brasil. Campinas: Editora da UNICAMP, 1989a.

. Da Análise da conversação para a análise gramatical. Estudos Linguísticos, 17, p. 219-226, 1989 b.

O Português Culto Falado no Brasil. PRETI, D; URBANO, H. (Org.). História do Projeto NURC/SP, 1990. p. 141-202.

. (Org.). Gramática do Português Falado. v. I: A Ordem. Campinas: Editora da

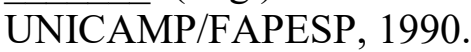

. (Org.). Gramática do Português Falado. v. III: As Abordagens. Campinas: Editora da UNICAMP/FAPESP, 1993.

. (Org.). Problemas de descrição da língua falada. D.E.L.T.A., 10 (1), p. 47-71, 1994.

Para uma sintaxe da repetição. Língua falada e gramaticalização. Língua e Literatura, 22, p. 293-332, 1997c (Universidade de São Paulo). Uma versão preliminar foi publicada como: "A repetição como processo constitutivo da gramática do português falado”. In: PADILLA, J. A. S; DÉNIZ, M. T. (Org.). Actas del XI Congreso de la Asociación de Lingüística y Filología de la América Latina. Las Palmas: Universidad de Las Palmas de Gran Canaria, tomo III, 2000. p. 2289-2298.

. A Língua falada no ensino do português. São Paulo: Editora Contexto, 1998a.

. (Org.). Para a História do Português Brasileiro. v. I: Primeiras ideias. São Paulo: Humanitas/FAPESP, 1998b.

Langue parlée et processus grammaticaux. In: BILGER, M.; VAN DEN EYNDE, K.; GADET, F. (Ed.). Analyse linguistique et approches de l'oral. Recueil d'études offert en hommage à Claire Blanche-Benveniste. Paris/Leuven: Peeters, 1998c. p. 141-148.

Aspectos teóricos de la descripción de la lengua hablada. In: BERNALES, M.; CONTRERAS, C. (Org.). Por los Caminos del Lenguaje. Temuco: Ediciones Universidad de La Frontera, 1998d. p. 23-37.

. Língua falada e processos gramaticais. In: GROSSE, S.; ZIMMERMANN, K. (Eds.). O Português brasileiro: pesquisas e projetos. Frankfurt am Main: TFM, 1998e. p. 37-72. 
Abordagem da língua como um sistema complexo. Contribuições para uma nova Linguística Histórica. In: CASTILHO, A. T. de; TORRES MORAIS, M. A.; LOPES, R. E. V.; CYRINO, S. M. L. (Org.). Descrição, história e aquisição do português brasileiro. Homenagem a Mary Kato. Campinas: Pontes/FAPESP, 2007. p. 329-360.

An approach to language as a complex system. In: CASTILHO, A. T. (Org.). História do Português Paulista. Campinas: Instituto de Estudos da Linguagem, 2009a. p. 119-136.

Para uma análise multissistêmica das preposições. In: CASTILHO, A. T. de (Org.). História do Português Paulista. Campinas: Instituto de Estudos da Linguagem, 2009b. p. 279-332.

A categoria cognitiva de movimento na gramática do Português. Refletindo sobre os achados dos Projetos NURC, PGPF e PHPB. In: DA HORA, D.; ALVES, E. F.; ESPÍNDOLA, L. C. (Org.). Abralin: 40 anos em cena. João Pessoa: Editora Universitária, 2009c. p. 71-96.

Análise multissistêmica da sentença matriz. In: OLIVEIRA E PAIVA, V. L. M. de; NASCIMENTO, M. do. (Org.). Sistemas adaptativos complexos. Lingua(gem) e aprendizagem. Belo Horizonte: Faculdade de Letras da UFMG, 2009d. p. 35-60.

Análise multissistêmica das minissentenças. In: RIBEIRO, S. S. C.; COSTA, S. B. B.; CARDOSO, S. A. M. (Org.). Miscelânea de estudos dedicados a Jacyra Motta. Salvador: Universidade Federal da Bahia, 2009e. p. 61-82.

Nova Gramática do Português Brasileiro. São Paulo: Editora Contexto, 2010a.

Para uma abordagem cognitivista-funcionalista da gramaticalização. In: DA HORA, D.; ROSA FILHO, C. (Org.). Para a História do Português Brasileiro. v. VIII. João Pessoa: Ideia / Editora Universitária, 2010b. p. 272-283.

Escrevendo gramáticas do português no séc. XXI. RAMOS, C. de M. A.; BEZERRA, J. de R. M.; ROCHA, M. de F. S.; RAZKY, A.; OLIVEIRA, M. B. de. (Org.). Pelos caminhos da Dialetologia e da Sociolinguística: entrelaçando saberes e vidas. Homenagem a Socorro Aragão. São Luís: Editora da Universidade Federal do Maranhão, 2010c. p. 206-222.

Produção bibliográfica do Projeto para a história do Português Brasileiro. In: DA HORA, D.; SILVA, C. R. (Org.). Para a História do Português Brasileiro. Abordagens e perspectivas. v. VIII. João Pessoa: Ideia / Editora da UFPb, 2010e. p. 395416.

. Some representations of MOTION in EP and BP standards. In: SILVA, A. S. da; TORRES, A.; GONÇALVES, M. (Org.). Línguas pluricêntricas. Variação linguística e dimensões sociocognitivas. Braga: Publicações da Faculdade de Filosofia da Universidade Católica de Braga, 2011. p. 45-60.

Princípio de projeção. In: SEDRINS, A. P. Por Amor à Linguística. Miscelânea de estudos linguísticos dedicados a Maria Denilda Moura. Maceió: Editora da Universidade Federal de Alagoas, 2012. p. 29-64.

. Funcionalismo e gramáticas do português brasileiro. In: SOUZA, E. R. de. Funcionalismo Linguístico. Novas tendências teóricas. São Paulo: Editora Contexto, 2012. p. 17-42. 
. Interação linguística e descrição do português brasileiro. Conferência lida no 11. Lusitanistentag, Aachen, 2015.

CASTILHO, A. T. de et alii. Diacronia da concordância. In: CASTILHO, A. T. de; MORAES DE, C.; LOPES, C. R. dos S. (Ed.). Historiando o Português Brasileiro. v. 5. 2016.

CASTILHO, A. T. de; ELIAS, W. M. Pequena gramática do português brasileiro. São Paulo: Editora Contexto, 2012.

CASTILHO, A. T. de; MORAES DE CASTILHO, C- M. Perspectiva multissistêmica da concordância. In: LIMA-HERNANDES, M. C.; MOURIVALDO, M.; SantiagoALMEIDA, M. M. (Org.). História do Português Paulista. Série Ensaios. v. 3. São Paulo, 2011. p. 111-132.

Aspectos da concordância verbal no português médio. In: ÁLVARES, R. et al. (Edición ao coidado de). III Congresso Internacional de Linguística Histórica. Universidad de Galicia, Santiago de Compostela, 2013. p. 107-124, edición electrónica.

CASTILHO, A. T. de; BASÍlLIO, M. (Org.). Gramática do Português Falado. v. IV. Estudos Descritivos. Campinas: Editora da UNICAMP/FAPESP, 1996.

CASTILHO, A. T.; PRETI, D. (Org.). A Linguagem Falada Culta na Cidade de São Paulo. Materiais para seu estudo. v. I: Elocuções Formais. São Paulo: TAQ/FAPESP, 1986.

. (Org.). A Linguagem Falada Culta na Cidade de São Paulo. Materiais para seu estudo. v. II. Diálogos entre dois informantes. São Paulo: TAQ/Fapesp, 1987.

DALL'AGLIO HATTNHER, M. M.; HENGEVELD, K. The Grammaticalization of Modal Verbs in Brazilian Portuguese: A Synchronic Approach. Journal of Portuguese Linguistics, v. 15, p. 1-14, 2016.

DEL CARRATORE, E.; LAPERUTTA FILHO, J. Léxico de frequência do Português falado na cidade de São Paulo (Projeto NURC). Marília/Botucatu, 2009. (CD-ROM).

DIAS DE MORAES, L. C. Nexos de Coordenação na Fala Urbana Culta de São Paulo. São Paulo, 1987.

DUARTE, M. E. L. Variação e sintaxe: clítico acusativo, pronome lexical e categoria vazia no português do Brasil. 1986. 150 f. Dissertação (Mestrado em Linguística) Pontifícia Universidade Católica, São Paulo, 1986.

DUARTE, M. E. L.; CALLOU, D. M. I. (Org.). Para a História do Português Brasileiro. v. IV: Notícias de corpora e outros estudos. Rio de Janeiro: UFRJ - Letras; FAPERJ, 2002.

FELÍCIO, C. P. Gramaticalização da conjunção concessiva 'embora'. 2008. $140 \mathrm{f}$. Dissertação (Mestrado em Estudos Linguísticos) - Instituto de Biociências, Letras e Ciências Exatas, Universidade Estadual Paulista, São José do Rio Preto, 2008.

FERNANDES, F. O. Construções com os verbos andar, continuar, ficar e viver seguidos de gerúndio: um estudo na interface Sociolinguística/Gramaticalização. 2010. $110 \mathrm{f}$. Iniciação científica (Licenciatura em Letras) - Instituto de Biociências, Letras e Ciências Exatas, Universidade Estadual Paulista, São José do Rio Preto, 2010. 
FERREIRA, J. S. O apagamento do /d/ em morfema de gerúndio no dialeto de São José do Rio Preto. 2010. 142 f. Dissertação (Mestrado em Estudos Linguísticos) - Instituto de Biociências, Letras e Ciências Exatas, Universidade Estadual Paulista, São José do Rio Preto, 2010.

FIAMENGUI, A. H. R. A marcação de pluralidade no SN na fala e na escrita de adolescentes da região de São José do Rio Preto. 2011. 142 f. Dissertação (Mestrado em Estudos Linguísticos) - Instituto de Biociências, Letras e Ciências Exatas, Universidade Estadual Paulista, São José do Rio Preto, 2011.

FONSECA, A. M. H. A perifrase verbal ir+infinitivo e o futuro do dialeto riopretano: um estudo na interface Sociolinguística/Gramaticalização. 2010. 172 f. Dissertação (Mestrado em Estudos Linguísticos) - Instituto de Biociências, Letras e Ciências Exatas, Universidade Estadual Paulista, São José do Rio Preto, 2010.

FONTES, M. G.; PEZATTI, E. G. As interrogativas de conteúdo na história do português brasileiro: uma abordagem discursivo-funcional. São Paulo: Cultura Acadêmica, 2012.

FORTILLI, S. C. As construções não-verbais no português falado no interior do Estado de São Paulo. 2007. 145 f. Dissertação (Mestrado em Estudos Linguísticos) - Instituto de Biociências, Letras e Ciências Exatas, Universidade Estadual Paulista, São José do Rio Preto, 2007.

. Predicados matrizes adjetivais de orações subjetivas no português brasileiro: gramaticalização e dessentencialização. 2013. 163 f. Tese (Doutorado em Estudos Linguísticos) - Instituto de Biociências, Letras e Ciências Exatas, Universidade Estadual Paulista, São José do Rio Preto, 2013.

GALBIATI, M. E. Análise comparativa do processo de gramaticalização das perífrases conjuncionais agora que $e$ já que. 2008. 188 f. Dissertação (Mestrado em Linguística e Língua Portuguesa) - Instituto de Biociências, Letras e Ciências Exatas, Universidade Estadual Paulista, São José do Rio Preto, 2008.

GARCIA, T. S. As relações concessivas no português falado sob a perspectiva da Gramática Discursivo-Funcional. 2010. 176 f. Tese (Doutorado em Estudos Linguísticos) - Instituto de Biociências, Letras e Ciências Exatas, Universidade Estadual Paulista, São José do Rio Preto, 2010.

GAVAZZI, S. C. Fechamentos em Entrevistas. Niterói: Universidade Federal Fluminense, 1998.

GIMENEZ, A. D'A. Estratégias de relativização e classes de palavras: um estudo tipológico-funcional. 2011. 162 f. Dissertação (Mestrado em Estudos Linguísticos) Instituto de Biociências, Letras e Ciências Exatas, Universidade Estadual Paulista Júlio de Mesquita Filho, São José do Rio Preto, 2011.

GONÇALVES, S. C. L. O português falado na região de São José do Rio Preto: constituição de um banco de dados anotado para o seu estudo. 2006. Relatório científico parcial II apresentado à FAPESP. Disponível em: $<$ http://www.iboruna.ibilce.unesp.br/histórico/relatorio2>. Acesso em: 22 jun. 2011. 
. O português falado na região de São José do Rio Preto: constituição de um

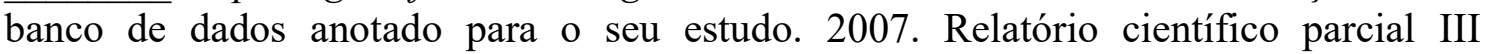
apresentado à FAPESP. Disponível em: $<$ http://www.iboruna.ibilce.unesp.br/histórico/relatorio3>. Acesso em: 22 jun. 2011.

Projeto ALIP (Amostra Linguística do Interior Paulista): questões teóricas e metodológicas sobre a constituição de um banco de dados de língua falada. In: TAGNIN, E.; VALE, O. A. (Org.). Avanços da Lingüistica de Corpus no Brasil. São Paulo: Humanitas, 2008. p. 217-245.

. Orações subjetivas: variância e invariância de padrões na fala e na escrita. Revista da ABRALIN, v. 10, p. 87-111, 2011.

Balanço crítico da Sociolinguística variacionista no Estado de São Paulo e a proposição de uma frente programática de investigação. Estudos Linguísticos, São Paulo, v. 41, n. 2, p. 869-884, 2012.

. Alçamento de constituintes argumentais sob perspectiva sociofuncionalista. Projeto de pesquisa financiado pelo CNPq. 2015.

GUERRA, A. R. Funções textual-interativas dos marcadores discursivos. 2007. 233 f. Dissertação (Mestrado em Estudos Linguísticos) - Instituto de Biociências, Letras e Ciências Exatas, Universidade Estadual Paulista, São José do Rio Preto, 2007.

HENGEVELD, K.; BECHARA, E. N.; CAMACHO, R. G.; GUERRA, A. R.; OLIVEIRA, T. P.; PENHAVEL, E.; PEZATTI, E. G.; SANTANA, L.; SOUZA, E. R. F. de; TEIXEIRA, M. L. de S. Basic illocutions in the native languages of Brazil. Alfa, São Paulo, v. 51, p. 73-90, 2007.

HENGEVELD, K.; DALL'AGLIO-HATTNHER, M. M. Four types of evidentiality in the native languages of Brazil. Linguistics, v. 53, p. 479-524, 2015.

HILGERT, J. G. (Org.). A Linguagem Falada Culta na Cidade de Porto Alegre. v. I: Diálogos entre informante e documentador. Passo Fundo: EDIUPF / Porto Alegre: Ed. Universidade/UFRGS, 1997.

HOFFNAGEL, J. C. A modalização epistêmica: usos e funções na fala e na escrita. Recife: UFPe, 1996.

HORA, D. da; ROSA, C. (Org.). Para a História do Português Brasileiro. v. VIII. João Pessoa: Universidade Federal da Paraíba, 2010.

ILARI, R. (Org.). Gramática do Português Falado. v. II: Níveis de Análise Linguística. Campinas: Editora da UNICAMP, 1992.

. Palavras de classe aberta. Gramática do Português Culto Falado no Brasil. v. III. São Paulo: Editora Contexto, 2014.

. Palavras de classe fechada. Gramática do Português Culto Falado no Brasil. v. IV. São Paulo: Editora Contexto, 2015.

ILARI, R.; NEVES, M. H. de M. (Org.). Gramática do Português Culto Falado no Brasil. v. II: Classes de palavras e construções. Campinas: Editora da UNICAMP, 2009.

JUBRAN, C. C. A. (Org.). Construção do texto falado. Gramática do Português Culto Falado no Brasil. v. I. São Paulo: Editora Contexto, 2015. 
JUBRAN, C. C. A.; KOCH, I. G. V. (Org.). Gramática do Português Culto Falado no Brasil. v. I: Construção do texto falado. Campinas: Editora da UNICAMP, 2006.

KATO, M. (Org.) Gramática do Português Falado. v. V: Convergências. Campinas: Editora da UNICAMP/FAPESP, 1996.

KATO, M.; NASCIMENTO, M. do (Org.). Gramática do Português Culto Falado no Brasil. v. III: Construção da sentença. Campinas: Editora da UNICAMP, 2008.

. (Org.). Construção da sentença. Gramática do Português Culto Falado no Brasil. v. II. São Paulo: Editora Contexto, 2015.

KOCH, I. G. V. (Org.) Gramática do Português Falado. v. VI. Campinas: Editora da UNICAMP/FAPESP, 1996.

LABOV, W. Sociolinguistic Patterns. Philadelphia: University of Pensylvania Press, 1972.

LIMA, A. C. Gramaticalização de orações avaliativas completivas do verbo achar. 2014. 162 f. Dissertação (Mestrado em Estudos Linguísticos) - Instituto de Biociências, Letras e Ciências Exatas de São José do Rio Preto, 2014.

LOBO, T. C. F.; RIBEIRO, I.; CARNEIRO, Z.; ALMEIDA, N. (Org.). Para a História do Português Brasileiro. v. VI: Novos dados, novas análises. 2 tomos. Salvador: Editora da Universidade Federal da Bahia, 2006.

LOPE-BLANCH, J. M. Proyecto de estudio del habla culta de las principales ciudades de Hispanoamérica. El Simposio de Bloomington. Bogotá: Instituto Caro y Cuervo, 1967 [1964]. p. 255-266.

. (Org.). Estudios sobre el español hablado. México: Universidad Nacional Autónoma de México, 1982.

. El estudio del español hablado. Historia de un proyecto. México: Universidad Nacional Autónoma de México, 1986.

MARCATO, F. Análise prosódica de clíticos preposicionais na variedade rio-pretense. 2013. 158 f. Dissertação (Mestrado em Estudos Linguísticos) - Instituto de Biociências, Letras e Ciências Exatas, Universidade Estadual Paulista, São José do Rio Preto, 2013.

MARCUSCHI, L. A. Análise da Conversação e Análise Gramatical, Boletim da ABRALIN 10, p. 11-34, 1991.

. Fala e Escrita no Continuum Tipológico. Recife: UFPe, 1997.

MARQUES, M. H. D. O Vocabulário da Fala Carioca. Rio de Janeiro: Faculdade de Letras da UFRJ, 1996. v. I: Ordem de Frequência Decrescente; v. II: Ordem Alfabética, Parte I (A-H); v. II: Ordem Alfabética, Parte II (I-Z); v. III: Substantivos. Ordem de Frequência Decrescente; v. IV: Verbos, Adjetivos, Unidades em -mente, Nomes próprios, Marcas e Siglas. Ordem de frequência decrescente; v. V: Substantivos. Ordem alfabética; v. VI: Verbos, Adjetivos, Unidades em -mente, Nomes próprios, Marcas e Siglas. Ordem Alfabética; v. VII: Instrumentos Gramaticais; v. VIII: Introdução: histórico, dados quantitativos e avaliação geral dos resultados.

MATtOS E SILVA, R. V. (Org.). Para a História do Português Brasileiro. v. II: Primeiros Estudos. 2 tomos. São Paulo: Humanitas/FAPESP, 2001. 
MENDES, R. B. SP2010: construção de uma amostra da fala paulistana. Projeto de pesquisa financiado pela FAPESP. São Paulo: Universidade de São Paulo, 2011.

MENON, O. P. S. Analyse sociolinguistique de l'indétermination du sujet dans le portugais parlé au Brèsil à partir des donnés du NURC/SP. 1994. Thèse (Doctorat)Université de Paris VII, Paris, 1994.

MOTTA, J.; ROLlEMBERG, V. (Org.). A Linguagem Falada Culta na Cidade de Salvador. Materiais para seu estudo. v. I: Diálogos entre Informante e Documentador. Salvador: Instituto de Letras da UFBa, 1994.

. (Org.). A Linguagem Falada Culta na Cidade de Salvador. Materiais para seu estudo. v. 2: Elocuções formais. Salvador: Instituto de Letras da UFBa / CNPq, 2006.

NARDELLI, A. J. S. Variação pronominal nós x a gente em interações dialógicas do interior paulista. 2017. Projeto de pesquisa (Iniciação Científica) - Instituto de Biociências, Letras e Ciências Exatas, Universidade Estadual Paulista, São José do Rio Preto, 2017.

NASCIMENTO, M. do. Notas sobre as atividades do Grupo de Sintaxe II. In: CASTILHO, A. T. de. (Org.). Gramática do português falado. v. III: As abordagens. 3. ed. Campinas: Editora da UNICAMP / Fapesp, 2002 [1993a]. p. 433-438.

. Gramática do Português Falado: articulação teórica, texto apresentado ao Centro de Linguística da Universidade de Lisboa. In: ZILLES, A. (Org.). Estudos de variação linguística no Brasil e no Cone Sul. Porto Alegre: Editora da Universidade Federal do Rio Grande do Sul, 2005. p. 93-116.

NEVES, M. H. M. (Org.). Gramática do Português Falado. v. VII. São Paulo / Campinas: Humanitas / Editora da UNICAMP, 1999.

. (Org.). Construção das orações complexas. Gramática do Português Culto Falado no Brasil. v. V. São Paulo: Editora Contexto, 2016.

Texto e gramática. São Paulo: Editora Contexto, 2013.

NOVAES-MARQUES, N. B.; PEZATTI, E. G. A relação conclusiva na língua portuguesa: funções resumo, conclusão e consequência. v. 1. São Paulo: Cultura Acadêmica, 2015.

OLIVEIRA, A. P. A relação adverbial temporal na lusofonia sob a perspectiva da Gramática Discursivo-Funcional. 2013. 117 f. Dissertação (Mestrado em Estudos Linguísticos) - Instituto de Biociências, Letras e Ciências Exatas, Universidade Estadual Paulista Júlio de Mesquita Filho, São José do Rio Preto, 2013.

OLIVEIRA, G.; CAMACHO, R. G. Estratégias de relativização e construções alternativas nas línguas indígenas do Brasil. São Paulo: Cultura Acadêmica, 2013.

PAIVA, V. L. M. de O. e; NASCIMENTO, M. Sistemas adaptativos complexos. Lingua(gem) e aprendizagem. Belo Horizonte: Faculdade de Letras, 2009.

PENHAVEL, E. Marcadores discursivos e articulação tópica. 2010. 168 f. Tese (Doutorado em Linguística) - Instituto de Estudos da Linguagem, Universidade Estadual de Campinas, Campinas, 2010.

PEZATTI, E. G. (Org.). Pesquisas em Gramática Funcional. Descrição do português. São Paulo: Fundação Editora da UNESP, 2009. 
PEZATTI, E. G.; CAMACHO, R. G.; NOVAES, N. B.; VALE, F. B. M. H.; BECHARA, E. N.; STASSI, J. C.; GUIRALDELLI, L.; OLIVEIRA, T. P.; COMPARINI, A. M. O estatuto lexical/gramatical das preposições no português. Lusorama, v. 81-82, p. 102$134,2010$.

PEZATTI, E. G. (Org.). Pesquisas em Gramática Funcional. Descrição do português. São Paulo: Editora da UNESP, 2011.

. (Org.). Construções subordinadas na lusofonia: uma abordagem discursivofuncional. São Paulo: Editora da UNESP, 2016.

PRETI, D. (Org.). Análise de Textos Orais. São Paulo: FFLCH/USP, 1993.

. (Org.). O Discurso Oral Culto. São Paulo: Humanitas Publicações FFLCH/USP, 1997.

. (Org.). Estudos de Língua Falada. Variações e confrontos. São Paulo: Humanitas, 1998.

. (Org.). Fala e Escrita em Questão. São Paulo: Humanitas, 2000.

. (Org.). Interação na Fala e na Escrita. São Paulo: Humanitas, 2002.

PRETI, D.; URBANO, H. (Org.) A Linguagem Falada Culta na Cidade de São Paulo. Materiais para seu estudo. v. III: Diálogos entre o Informante e o Documentador. São Paulo: TAQ/FAPESP, 1988.

PRETI, D.; URBANO, H. (Org.). A Linguagem Falada Culta na Cidade de São Paulo. v. IV: Estudos. São Paulo: TAQ/FAPESP, 1990.

RAMOS, A. P. Descrição das vogais postônicas não-finais na variedade do noroeste paulista. 2009. 177 f. Dissertação (Mestrado em Estudos Linguísticos) - Instituto de Biociências, Letras e Ciências Exatas, Universidade Estadual Paulista, São José do Rio Preto, 2009.

RAMOS, J.; ALCKMIN, M. A. (Org.). Para a História do Português Brasileiro. v. V: Estudos sobre mudança linguística e história social. Belo Horizonte: Faculdade de Letras da Universidade Federal de Minas Gerais, 2007.

RENCK, N. R. Renovação e gramaticalização: o caso da locução conjuntiva. Iniciação científica) - Instituto de Biociências, Letras e Ciências Exatas, Universidade Estadual Paulista / FAPESP, São José do Rio Preto [no prelo].

RODRIGUES, A. C. S. A concordância verbal no português popular em São Paulo. 1987. Tese (Doutorado em Língua Portuguesa) - Faculdade de Filosofia, Letras e Ciências Humanas, Universidade de São Paulo, São Paulo, 1987.

RODRIGUES, A. N. O dialeto caipira na região de Piracicaba. São Paulo: Ática, 1974.

RONCARATI, C. Banco de dados interacionais. Rio de Janeiro: Universidade Federal do Rio Janeiro, 1996.

ROSSAFA, V. Padrões de concordância verbal referentes à primeira pessoa do plural em interações dialógicas do interior paulista. Projeto de pesquisa (Iniciação Científica) - Instituto de Biociências, Letras e Ciências Exatas, Universidade Estadual Paulista, São José do Rio Preto, 2016.

ROSSI, N. A Dialetologia. Alfa, 11, 1967. 
. (1968/1969). El Proyecto de Estudio del Habla Culta y su ejecución en el dominio de la lengua portuguesa. In: El Simposio de México. México: Universidad Nacional Autónoma de México, 1969. p. 248. Republicado em: CASTILHO, A. T. (Org. 1970). Projeto de estudo da norma linguística urbana culta no Brasil. Marília: Conselho Municipal de Cultura, 1970. p. 2-15.

RUBIO, C. F. A concordância verbal na região noroeste do Estado de São Paulo. 2008. 152 f. Dissertação (Mestrado em Estudos Linguísticos) - Instituto de Biociências, Letras e Ciências Exatas, Universidade Estadual Paulista, São José do Rio Preto, 2008.

Padrões de concordância verbal e de alternância pronominal no português brasileiro e europeu: estudo sociolinguístico comparativo. 2012. $391 \mathrm{f}$. Tese (Doutorado em Estudos Linguísticos) - Instituto de Biociências, Letras e Ciências Exatas, Universidade Estadual Paulista, São José do Rio Preto, 2012.

SÁ, M. P. M.; CUNHA, D. A. C. da; LIMA, A. M.; OLIVEIRA JR., M. (Org.). A Linguagem Falada Culta na Cidade do Recife. v. I: Diálogos entre informante e documentador. Recife: Universidade Federal de Pernambuco, Programa de PósGraduação em Letras e Linguística, 1996.

. (Org.). A Linguagem Falada Culta na Cidade do Recife. v. 2: Elocuções formais. Recife: Universidade Federal de Pernambuco, Programa de Pós-Graduação em Letras e Linguística, 2005.

SALOMÃO, M. H. A variação de pluralidade nas estruturas predicativas da variedade falada na região de São José do Rio Preto. 2010. 160 f. Dissertação (Mestrado em Estudos Linguísticos) - Instituto de Biociências, Letras e Ciências Exatas, Universidade Estadual Paulista, São José do Rio Preto, 2010.

SANTANA, L. Relações de complementação no português brasileiro: uma perspectiva discursivo-funcional. São Paulo: Cultura Acadêmica, 2010.

SANTOS, R. M. A. A alternância indicativo/subjuntivo em estruturas complexas. 2005. 152 f. Dissertação (Mestrado em Estudos Linguísticos) - Instituto de Biociências, Letras e Ciências Exatas, Universidade Estadual Paulista, São José do Rio Preto.

SILVA, A. C. B. Estilos na cultura popular urbana. 2010. Projeto de pesquisa. FAPESP, Universidade de São Paulo, São Paulo.

SILVEIRA, A. A. M. As vogais pretônicas na fala culta do noroeste paulista. 2008. 142 f. Dissertação (Mestrado em Estudos Linguísticos) - Instituto de Biociências, Letras e Ciências Exatas, Universidade Estadual Paulista, São José do Rio Preto, 2008.

SOUZA, E. R. F. Gramaticalização dos itens linguísticos 'assim', 'já' e 'aí' no português brasileiro: um estudo sob a perspectiva da gramática discursivo-funcional. 2009. $290 \mathrm{f}$. Tese (Doutorado em Linguística) - Instituto de Estudos da Linguagem, Universidade Estadual de Campinas, Campinas, 2009.

SPOSITO, C. C. Construções adverbiais de Causa, Razão, Explicação e Motivação na lusofonia: uma abordagem discursivo-funcional. 2012. 145 f. Dissertação (Mestrado em Estudos Linguísticos) - Instituto de Biociências, Letras e Ciências Exatas, Universidade Estadual Paulista Júlio de Mesquita Filho, São José do Rio Preto, 2012. 
STASSI-SÉ, J. C. Subordinação discursiva no português à luz da Gramática DiscursivoFuncional. 2012. 194 f. Tese (Doutorado em Estudos Linguísticos) - Instituto de Biociências, Letras e Ciências Exatas, Universidade Estadual Paulista, São José do Rio Preto, 2012.

VENDRAME, V. Os verbos ver, ouvir e sentir e a expressão de evidencialidade em língua portuguesa. 2010. $173 \mathrm{f}$. Tese (Doutorado em Estudos Linguísticos) - Instituto de Biociências, Letras e Ciências Exatas, Universidade Estadual Paulista, São José do Rio Preto, 2010.

VOTRE, S.; OLIVEIRA, M. R. A Lingua falada e escrita na cidade do Rio de Janeiro: materiais para seu estudo. Rio de Janeiro: UFRJ, 1995.

WIEDEMER, M. L. Variação e gramaticalização de preposições de complementos locativos de verbos de movimento. 2013. 248 f. Tese (Doutorado em Estudos Linguísticos) - Instituto de Biociências, Letras e Ciências Exatas, Universidade Estadual Paulista, São José do Rio Preto, 2013.

Recebido em: 30/09/2016

Aprovado em: 29/11/2016 